\title{
Prognostic Significance of Preoperative Anemia in Patients Undergoing Surgery for Renal Cell Carcinoma: A Meta-analysis
}

\author{
LEILEI XIA ${ }^{1}$, GUODONG HU ${ }^{1,2}$ and THOMAS J. GUZZO ${ }^{1}$ \\ ${ }^{1}$ Division of Urology, Department of Surgery, \\ University of Pennsylvania Perelman School of Medicine, Philadelphia, PA, U.S.A.; \\ ${ }^{2}$ Department of Urology, Shenyang Red Cross Hospital, Shenyang, P.R. China
}

\begin{abstract}
Aim: To better evaluate the association between preoperative anemia and outcomes in patients following radical or partial nephrectomy for renal cell carcinoma (RCC). Materials and Methods: A meta-analysis of hazard ratios (HR) was conducted to measure the association between preoperative anemia and all-cause mortality $(A C M)$, cancerspecific mortality (CSM), and disease recurrence (DR) in patients who underwent surgery for RCC. Results: A total of 14 studies (8,673 patients) met the eligibility criteria. All studies reported survival outcomes using the multivariable Cox proportional hazards model. Pooled results showed that preoperative anemia was associated with increased ACM [HR $=2.13,95 \%$ Confidence Interval $(C I)=1.48-3.06], C S M$ (HR=1.91, 95\% CI=1.26-2.90), and DR (HR=1.67, 95\% $C I=1.16-2.40$ ). Conclusion: This meta-analysis indicates that preoperative anemia appears to be associated with earlier recurrence and shorter survival of patients undergoing radical or partial nephrectomy for RCC. Our findings, however, still need to be validated by well-designed prospective studies with larger sample sizes and well-controlled confounding factors.
\end{abstract}

Due to the increased use of cross-sectional and diagnostic imaging modalities, there has been an increased incidence in the detection of localized renal cell carcinoma (RCC) (1). For localized RCC, surgery remains the standard of care and is associated with the best oncological outcomes. Accordingly, there have been increasingly more surgical interventions for localized RCC, most notably radical and partial nephrectomy. Despite the improvement in surgical techniques, approximately $20-40 \%$ of patients with localized RCC will still eventually

Correspondence to: Leilei Xia, MD, Perelman Center for Advanced Medicine, West Pavilion, 3rd Floor, 3400 Civic Center Boulevard, Philadelphia, PA 19104, U.S.A. Tel: +1 2156622891, Fax: +1 2156623955,e-mail: leilei.xia@uphs.upenn.edu

Key Words: Renal cell carcinoma, anemia, hemoglobin, mortality, meta-analysis. develop metastatic disease after surgery $(1,2)$. Although several prognostic models have been developed for patients undergoing surgery for RCC, there remains a need to identify other potential prognostic markers, particularly preoperative ones, to stratify patients with RCC (3).

There has been growing interest in the prognostic role of complete blood count-based biomarkers in patients with RCC. The neutrophil-lymphocyte ratio, lymphocyte-monocyte ratio, neutrophil cell count, and platelet count have all been reported as promising biomarkers for predicting oncological outcomes in patients with RCC (3-5). However, the prognostic role of anemia in patients with RCC, in particular patients undergoing radical or partial nephrectomy, has not been clearly defined.

Anemia is relatively common in patients with malignant tumors, including RCC (6). The number of studies providing data on the association between anemia and survival outcomes is increasing (7-20). Nevertheless, the prognostic role of anemia in patients undergoing surgery for RCC was not very consistent in published studies due to the study design and small sample size. For instance, based on the multivariate Cox proportional hazards model, three studies concluded a significant association between anemia and worse cancer-specific survival $(11,14,15)$, while another four studies did not report such an association $(12,17,18,20)$. Here, we performed a meta-analysis to pool all the evidence on this topic and further determine the prognostic role of anemia status in patients with RCC undergoing surgery.

\section{Materials and Methods}

Search strategy. This meta-analysis was conducted following guidance from the Preferred Reporting Items for Systematic Reviews and Meta-Analyses (PRISMA) statement (21). A comprehensive search of the literature was performed on June 2016 in the PubMed and EMBASE. The following full search strategy was used for both PubMed and EMBASE: (renal cell carcinoma OR kidney cancer) AND (nephrectomy) AND (anemia OR hemoglobin OR hematocrit) AND (mortality OR survival). We applied no restrictions on publication type, language or year. References from the selected articles were manually searched and assessed for additional studies. 
Selection criteria. An original research study was considered eligible if it met the following inclusion criteria: (i) it had a retrospective or prospective cohort of patients with RCC who underwent radical or partial nephrectomy with curative intent; (ii) it included at least 100 patients; (iii) it assessed the association between preoperative anemia status and oncological outcomes with Cox proportional hazards model; (iv) it reported at least one of the outcomes of interest, which were determined as all-cause mortality (ACM), cancer-specific mortality (CSM), and disease recurrence (DR); (v) it provided the hazard ratios (HRs) and 95\% confidence intervals (CIs) or $p$-value with the HRs. Studies that reported outcomes in patients with metastatic RCC or patients undergoing cytoreductive nephrectomy were excluded. If two or more studies had a duplicate patient cohort, only the study with the largest sample size or the study with the longest follow-up time was included.

Data extraction. The following variables were extracted from each included study: first author, year of publication, country of origin, recruitment period, study design, anemia cutoff value, number of patients, age, gender, follow-up time, tumor size, tumor side, pathologic $\mathrm{T}$ stage, pathologic N stage, pathologic type, Fuhrman grade, type of surgery, and HRs (95\% CIs) of the outcomes of interest. HRs from multivariable Cox regression were extracted if both univariable and multivariable Cox regression were used, otherwise, data from univariable Cox regression was extracted.

Risk of bias assessment. Quality in Prognosis Studies (QUIPS) tool was used to evaluate the quality of included studies in six domains: study participation, study attrition, prognostic factor measurement, outcome measurement, study confounding, and statistical analysis and reporting (22). Each domain was rated as high, moderate, or low risk of bias in each study based on the prompting items and considerations in QUIPS tool. Then the overall risk of bias in each study was rated as high, moderate, or low risk of bias based on the individual ratings of each domain.

Statistical analysis. HRs and 95\% CIs were meta-analyzed to assess the association of preoperative anemia and ACM, CSM, and DR in patients undergoing surgery for RCC. Study heterogeneity was quantified by $\mathrm{I}^{2}$ value and only the random-effect model was used. Publication bias was assessed with funnel plot. All the $p$-values were two-sided and a value of $p<0.05$ was considered statistically significant. Review Manager 5.3 (The Nordic Cochrane Centre, Copenhagen, Denmark) was used for all the analyses and plots.

To explore the robustness of the results, we performed sensitivity analysis and subgroup analysis for ACM, considering it had the largest number of included studies compared with CSM and DR. We excluded one study at a time and calculated the pooled HRs from the remaining studies for the sensitivity analysis. Subgroup analyses were conducted based on the following factors: study quality (low risk of bias $v s$. moderate risk of bias), sample size $(\geq 400 v s .<400)$, and pathological type (clear cell $v s$. papillary $v s$. mixed $v s$. unclear).

\section{Results}

Literature search. We identified 378 references from the preliminary search. After excluding 60 duplicate publications, 318 references were left for screening. We excluded 277 references after reviewing the titles/abstracts and included 41 studies for full-text review. Finally, 14 studies fulfilled the inclusion criteria and provided data relevant for meta-analyses (7-20). The flow diagram of the study selection is shown in Figure 1.

Characteristics of included studies. The main characteristics of the included studies are summarized in Table I. Included studies were published between 2007 and 2016 and all of them were retrospective in study design. The hemoglobin cutoff value for anemia varied among studies (11.3-13.5 g/dl for both male and female). HRs and $95 \%$ CIs or $p$-values were obtained from original studies directly and all of the studies used the multivariate Cox proportional hazards model. The cofactors accounted for in the included studies are shown in Supplementary Table I (https://www.researchgate.net/ publication/316124361_Supplementary_Materials). Seven studies $(7,9,11,12,14,15,18)$ had a low risk of bias and another seven $(8,10,13,16,17,19,20)$ had a moderate risk of bias based on the assessment with QUIPS tool (Supplementary Table II) (https://www.researchgate.net/ publication/316124361_Supplementary_Materials).

Patient, tumor, and surgical characteristics of the included studies are summarized in Table II. The current metaanalysis included a total of 8,673 patients ranging from 101 to 2,865 per study. Patient age ranged from 64.8 to 71.1 years. Follow-up time ranged from 16 months to 124 months. Most of the patients had pathological T stages 1-2, and $\mathrm{N}$ stage of $\mathrm{Nx}-0$. Three studies reported only patients with clear cell $\operatorname{RCC}(8,13,16)$, one study reported only patients with papillary RCC (11), eight studies reported patient cohorts with mixed type RCC $(9,10,12,14,15,17$, $18,20)$, and another two studies did not specify the pathological type $(7,19)$.

Meta-analysis. Pooled results of ACM, CSM, and DR are shown in Figure 2. Pooled results from eight studies with 5300 patients $(8,10,11,13,15,16,18,19)$ showed that compared with non-anemia, anemia was associated with increased ACM $\left(\mathrm{HR}=2.13,95 \% \mathrm{CI}=1.48-3.06, p<0.0001, \mathrm{I}^{2}=78 \%\right)$. Pooled results from seven studies with 6558 patients $(11,12,14,15$, $17,18,20)$ showed that anemia was associated with increased CSM (HR $\left.=1.91,95 \% \mathrm{CI}=1.26-2.90, p=0.002, \mathrm{I}^{2}=73 \%\right)$ compared with non-anemia. Seven studies with 3,073 patients $(7,9-11,13,14,17)$ provided data on the association between preoperative anemia and DR and the results suggest that anemia was associated with increased DR (HR $=1.67,95 \%$ $\left.\mathrm{CI}=1.16-2.40, p=0.006, \mathrm{I}^{2}=58 \%\right)$.

Sensitivity analysis and subgroup analysis of ACM are shown in Supplementary Table III and Supplementary Table IV, respectively (https://www.researchgate.net/publication/31612 4361_Supplementary_Materials). Pooled HRs of the remaining studies ranged from 1.89 to 2.41 after excluding one study at a time. No individual study had a significant impact on the 


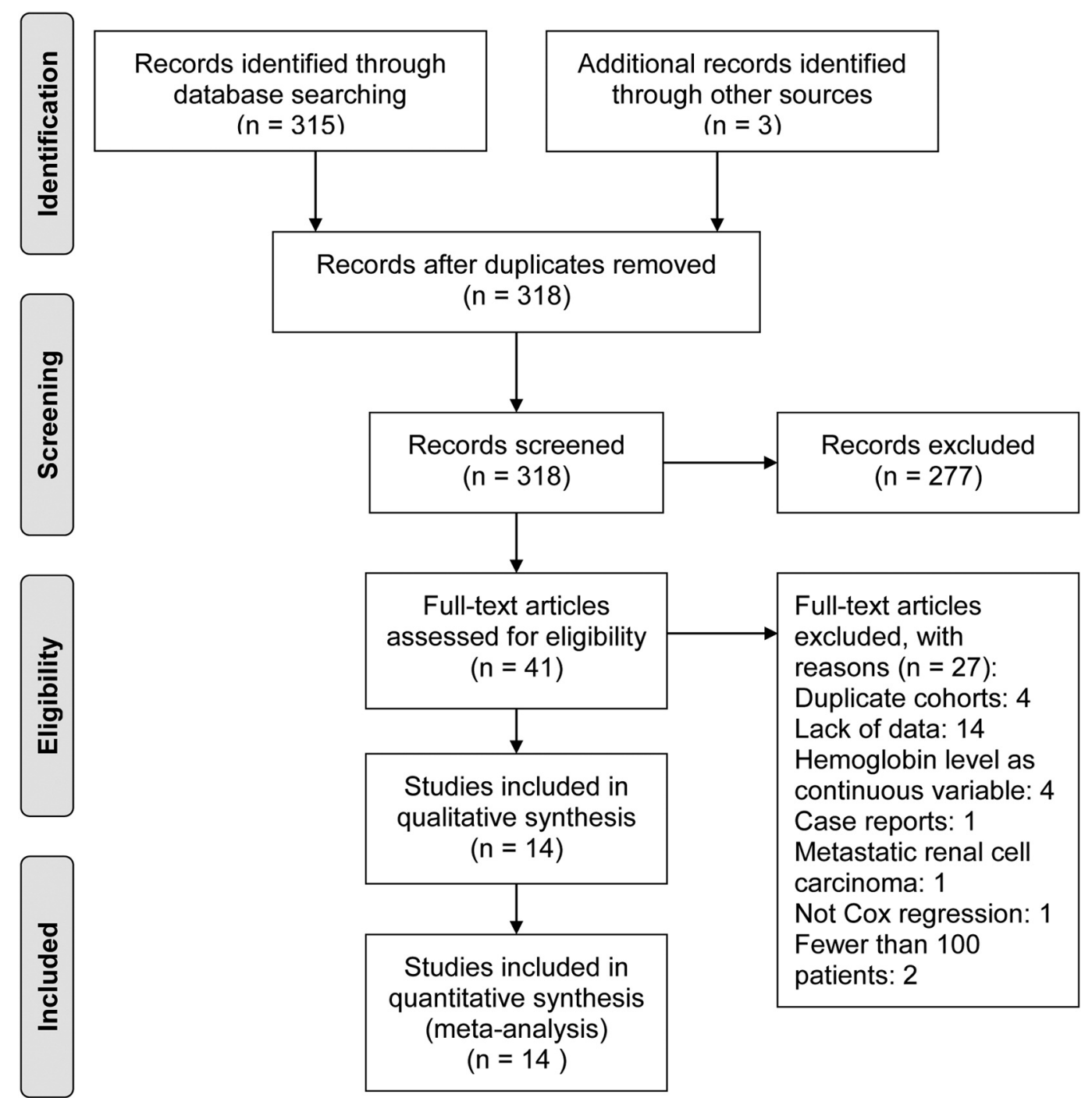

Figure 1. Flow diagram of study selection.

pooled effect based on the sensitivity analysis. The findings of increased ACM were also consistent in all subgroups except for the group of unclear pathology (one study). Visual inspection of the funnel plots revealed no obvious publication bias (Supplementary Figure 1) (https://www.researchgate.net/ publication/316124361_Supplementary_Materials).

\section{Discussion}

Identification of risk factors for disease recurrence and mortality is critical to the management of any type of cancer. In this meta-analysis, we included 14 cohort studies with 8,673 patients and found a possible association between preoperative anemia and oncological outcomes in patients with RCC who underwent nephrectomy. Our meta-analysis suggests that compared with non-anemia, preoperative anemia appears to be significantly associated with increased ACM, CSM, and DR. To the best of our knowledge, this is the first meta-analysis evaluating the prognostic role of preoperative anemia in patients undergoing surgery for RCC.

One previous systematic review on the topic of anemia as a prognostic factor in patients with cancer was published in 2001 (23). The authors included 60 studies and concluded that anemia was associated with shorter survival times in patients with lung cancer, cervico-uterine cancer, head and neck cancer, prostate cancer, lymphoma, and multiple myeloma (23). However, most of the included studies of solid tumors reported survival outcomes in patients with advanced cancer (23). For 
Table I. Main characteristics of the included studies (all retrospective).

\begin{tabular}{|c|c|c|c|c|c|c|}
\hline Study (Ref) & Year & Country & $\begin{array}{l}\text { Recruitment } \\
\text { period }\end{array}$ & $\begin{array}{l}\text { Hemoglobin cutoff for anemia } \\
\text { (male/female, } \mathrm{g} / \mathrm{dl})\end{array}$ & $\begin{array}{l}\text { Outcome(s) of } \\
\text { interest }\end{array}$ & $\begin{array}{l}\text { Risk of } \\
\text { bias }^{\dagger}\end{array}$ \\
\hline Brookman-Amissah et al. (7) & 2009 & Germany & $1992-2006$ & $11.3 / 11.3$ & $\mathrm{DR}$ & Low \\
\hline Chen et al. (8) & 2015 & China & 2003-2012 & $11.6 / 11.6$ & $\mathrm{OM}$ & Moderate \\
\hline Cho et al. (9) & 2011 & Korea & $2000-2008$ & Unclear & DR & Low \\
\hline Grivas et al. (10) & 2014 & Greece & $1996-2011$ & $13.5 / 12.0$ & $\mathrm{OM}$ & Moderate \\
\hline Huang et al. (11) & 2015 & USA, China & $1991-2011$ & $13.5 / 12.0$ & OM, CSM, DR & Low \\
\hline Hutterer et al. (12) & 2015 & Austria & 2004-2012 & $13.2 / 13.2$ & CSM & Low \\
\hline Jensen et al. (13) & 2009 & Denmark & $1992-2001$ & Unclear & $\mathrm{DR}$ & Moderate \\
\hline Jeon et al. (14) & 2016 & Korea & $1994-2008$ & $13.5 / 12.0$ & OM, CSM, DR & Low \\
\hline Kaffenberger et al. (15) & 2015 & USA & $2000-2010$ & $13.5 / 12.0$ & OM, CSM & Low \\
\hline Koie et al. (16) & 2014 & Japan & $1992-2013$ & Unclear & $\mathrm{OM}$ & Moderate \\
\hline Komai et al. (17) & 2007 & Japan & $1986-2004$ & $13.0 / 12.0$ & CSM, DR & Moderate \\
\hline Moreira et al. (18) & 2016 & USA & $1990-2010$ & $13.5 / 12.0$ & $\mathrm{OM}, \mathrm{CSM}$ & Low \\
\hline Sasaki et al. (19) & 2015 & Japan & $2003-2013$ & $12.0 / 12.0$ & $\mathrm{OM}$ & Moderate \\
\hline Yap et al. (20) & 2013 & Malaysia & 2003-2012 & $13.0 / 12.0$ & CSM & Moderate \\
\hline
\end{tabular}

Table II. Patient, tumor and surgical characteristics of the included studies.

\begin{tabular}{|c|c|c|c|c|c|c|c|c|c|c|c|}
\hline Study (Ref) & $\begin{array}{c}\text { No. } \\
\text { of } \\
\text { patients }\end{array}$ & $\begin{array}{l}\text { Mean } \\
\text { age } \\
\text { (years) }\end{array}$ & $\begin{array}{l}\text { Male/ } \\
\text { female }\end{array}$ & $\begin{array}{l}\text { Anemia } \\
\text { status, } \\
\text { yes/no }\end{array}$ & $\begin{array}{c}\text { Mean } \\
\text { follow-up } \\
\text { (months) }\end{array}$ & $\begin{array}{l}\text { Mean } \\
\text { tumor } \\
\text { size } \\
(\mathrm{cm})\end{array}$ & $\begin{array}{c}\text { T-Stage: } \\
\text { T1/2/ } \\
3 / 4\end{array}$ & $\begin{array}{c}\text { N-Stage } \\
(\mathrm{Nx}-0 / \\
\mathrm{N} 1)\end{array}$ & $\begin{array}{c}\text { Histology } \\
\text { (clear/papillary/ } \\
\text { chromophobe/ } \\
\text { other) }\end{array}$ & $\begin{array}{l}\text { Fuhrman } \\
\text { grade } \\
(1 / 2 / 3 / 4)\end{array}$ & $\begin{array}{c}\text { Surgery: } \\
\text { radical/ } \\
\text { partial }\end{array}$ \\
\hline $\begin{array}{l}\text { Brookman-Amissah } \\
\text { et al. (7) }\end{array}$ & 771 & 61.1 & $488 / 283$ & $58 / 713$ & 75.7 & NR & NR & NR & NR & NR & $653 / 118$ \\
\hline Chen et al. (8) & 406 & $58 \dagger$ & $253 / 153$ & $57 / 349$ & 63 & NR & $340 / 39 / 26 / 1$ & $395 / 11$ & $406 / 0 / 0 / 0$ & NR & NR \\
\hline Cho et al. (9) & 177 & 53.5 & $130 / 47$ & $12 / 165$ & 48.3 & 5.12 & $129 / 12 / 36 / 0$ & NR & $160 / 8 / 7 / 2$ & $35 / 54 / 73 / 15$ & $177 / 0$ \\
\hline Grivas et al. (10) & 114 & $64 \dagger$ & $80 / 34$ & $26 / 77$ & $69^{\dagger}$ & NR & $71 / 13 / 30 / 0$ & NR & $90 / 15 / 5 / 4$ & $23 / 64 / 21 / 6$ & $104 / 0$ \\
\hline Huang et al. (11) & 352 & 60.1 & $277 / 75$ & $108 / 244$ & $49^{\dagger}$ & $3.5^{\dagger}$ & $256 / 31 / 68 / 0$ & $340 / 12$ & $0 / 352 / 0 / 0$ & $249 / 103^{\ddagger}$ & NR \\
\hline Hutterer et al. (12) & 736 & 63.7 & $451 / 285$ & $277 / 459$ & $16^{\dagger}$ & 4.6 & $\begin{array}{c}493 / 49 / \\
188 / 6\end{array}$ & NR & $596 / 97 / 36 / 7$ & $\begin{array}{c}187 / 400 / \\
141 / 8\end{array}$ & NR \\
\hline Jensen et al. (13) & 121 & $61^{\dagger}$ & $74 / 37$ & NR & $124^{\dagger}$ & 7 & $51 / 17 / 49 / 4$ & $112 / 9$ & $121 / 0 / 0 / 0$ & $4 / 60 / 39 / 18$ & $121 / 0$ \\
\hline Jeon et al. (14) & 1437 & 54.2 & $1011 / 426$ & NR & 68.6 & 5.1 & $\begin{array}{c}1031 / 197 / \\
181 / 28\end{array}$ & $1402 / 35$ & $1236 / 201^{\S}$ & $\begin{array}{l}54 / 632 / \\
623 / 128\end{array}$ & NR \\
\hline Kaffenberger et al. (15) & 916 & $60.8^{\dagger}$ & $594 / 322$ & $268 / 641$ & $42.5^{\dagger}$ & NR & $\begin{array}{c}538 / 102 / \\
253 / 23\end{array}$ & $862 / 54$ & $665 / 251^{\S}$ & $566 / 316^{\ddagger}$ & $584 / 332$ \\
\hline Koie et al. (16) & 400 & NR & $286 / 114$ & $71 / 329$ & $36^{\dagger}$ & NR & $261 / 41 / 88 / 10$ & $384 / 16$ & $400 / 0 / 0 / 0$ & NR & NR \\
\hline Komai et al. (17) & 101 & $64 \dagger$ & $63 / 38$ & $27 / 74$ & $55^{\dagger}$ & NR & $63 / 16 / 22 / 0$ & NR & $97 / 4 \S$ & $63 / 33 / 5 / 0$ & $101 / 0$ \\
\hline Moreira et al. (18) & 2865 & $64 \dagger$ & $1916 / 949$ & $\begin{array}{c}661 / 529 / \\
1633^{*}\end{array}$ & $63.6^{\dagger}$ & 4.5 & $\begin{array}{c}1959 / 381 / \\
502 / 23\end{array}$ & NR & $\begin{array}{c}2162 / 477 / \\
172 / 54\end{array}$ & $\begin{array}{c}235 / 1459 / \\
1021 / 150\end{array}$ & $\begin{array}{l}1625 / \\
1240\end{array}$ \\
\hline Sasaki et al. (19) & 126 & $67^{\dagger}$ & $84 / 42$ & NR & $30.8^{\dagger}$ & 4.6 & NR & NR & NR & NR & $105 / 0$ \\
\hline Yap et al. (20) & 151 & 60.7 & $101 / 50$ & NR & $26^{\dagger}$ & 6.5 & NR & NR & $120 / 13 / 3 / 1$ & $11 / 50 / 24 / 10$ & $104 / 17$ \\
\hline
\end{tabular}

$\dagger$ Median. *Given as anemia only/gross hematuria/no anemia or gross hematuria (total 2823). ¥Shown as 1-2/3-4. \$Given as clear/non-clear. NR: Not reported.

RCC, only one study was included in the review and it also only focused on patients with metastatic RCC (23). Therefore, aside from the specific cancer type, another major strength of our meta-analysis is the selection of patients undergoing curative surgery. It is obvious that localized RCC and advanced $\mathrm{RCC}$ have differences in both management and prognosis. The setting of our meta-analysis renders our conclusion more reliable and more focused in terms of clinical significance. Our 


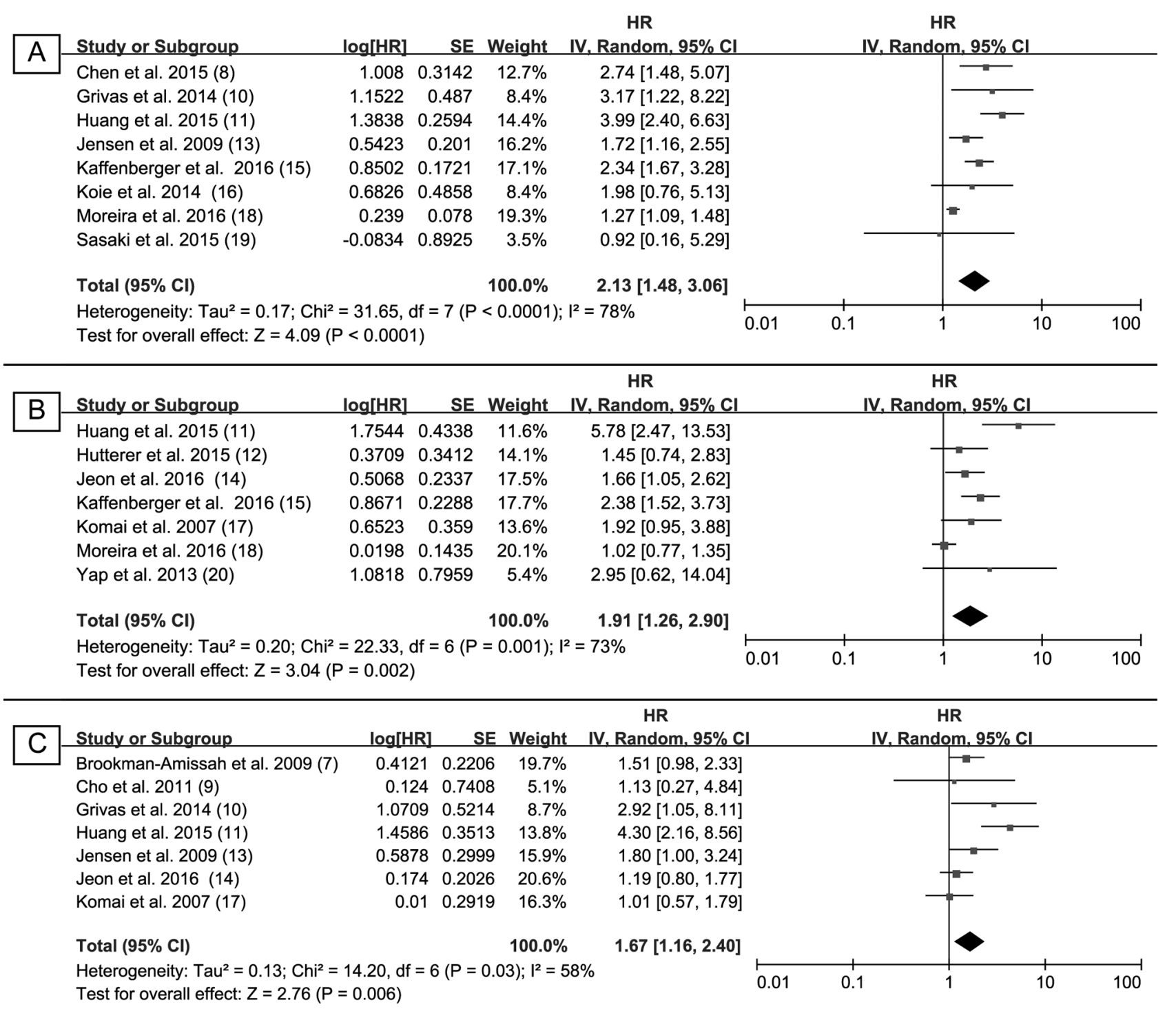

Figure 2. Forest plots showing the association between preoperative anemia and all-cause mortality (A), cancer-specific mortality (B), and disease recurrence $(C)$.

findings are also consistent with results from primary studies focusing on different types of cancer. For instance, preoperative anemia was reported as an independent predictor of worse survival outcomes in patients with upper tract urothelial carcinoma (24) and muscle-invasive bladder cancer (25).

Overall, our results are well supported by previous studies. In the meantime, we should always interpret this type of meta-analysis cautiously. One possible explanation for these findings is that anemia may be related to a higher cancer stage, grade, and burden $(11,24,26)$. Anemia in patients with cancer is usually derived from multiple factors and a wide range of mechanisms, such as bone marrow infiltration, erythrophagocytosis, hemolysis, amyloidosis, and red cell aplasia, all of which indicate tumor aggressiveness (26). It is also very likely that patients with more aggressive RCCs have a lower hemoglobin level resulting from acute or chronic hematuria. However, there might be other possible factors underlying the associations between preoperative anemia and survival outcomes. For example, patients with anemia have a lower threshold for perioperative transfusion, which has been reported to have a negative effect on survival in patients with RCC after nephrectomy (27). In addition, tumor hypoxia from anemia may indeed have some influence on the aggressiveness of cancer. It is well established that hypoxiainducible factor (HIF) can target vascular endothelial growth factor and platelet-derived growth factor, both of which are 
related to angiogenesis, a key factor determining the invasiveness of cancer cells $(26,28)$. A recent meta-analysis showed that increased nuclear expression of HIF1 $\alpha$ and cytoplasmic expression of HIF2 $\alpha$ indicate unfavorable prognosis in patients with RCC (28). Based on our results and previous literature, anemia might not be just a proxy of tumor stage, aggressiveness or burden, but also be a significant independent predictor of survival outcome (26).

Therefore, our meta-analysis may have multiple implications for clinical practice. Firstly, stratification by anemia status could be used to counsel patients regarding their overall prognosis. Secondly, preoperative hemoglobin level or anemia status can be regarded as a potential marker to guide the management of clinical localized RCCs or facilitate the decision-making, including clinical trial entry. Thirdly, preoperative anemia might also raise the flag for more intensive postoperative follow-up and possible treatment. Pathological diagnosis and assessment are the key factors in determining the postoperative follow-up and management strategy, but the hemoglobin level might provide additional information. In general, the hemoglobin level is routinely checked in the clinical setting, which means anemia status can potentially provide readily available and objective information to help clinicians to estimate patient outcome.

Although well-designed prospective studies are still needed to confirm our results, our meta-analysis does have some implications for future research. One potential area of interest is to incorporate the hemoglobin level or anemia status into the existing prognostic and predictive tools for patients with RCC or develop new predictive tools in which hemoglobin level is included (3). Most of the existing models do not take the hemoglobin level into consideration $(3,29,30)$. Another promising research topic is the treatment of preoperative anemia in patients with RCC to determine how the treatment may affect the long-term survival outcomes after nephrectomy (26). The prognostic role of anemia or the hemoglobin level in metastatic RCCs is also worth further investigation, such as following the hemoglobin level in patients on clinical trials to see if it can serve as a surrogate for a therapy response.

There are some additional limitations of our study that must be pointed out. Firstly, the retrospective study design of all included studies and the lack of detailed information on confounding factors might bias the results. Co-factors accounted for were different among included studies even though all of them used multivariate Cox regression analysis. Moreover, it is very hard, if not impossible, to control the confounding factors in a study-level meta-analysis. Secondly, the duration of followup varied among studies and only six studies had a mean or median follow-up time longer than 60 months. In addition, different cutoff values for anemia were used. Finally, heterogeneities existed in all the outcomes of interest with all $\mathrm{I}^{2}$ values being larger than $50 \%$ in the primary analyses. Sensitivity analyses showed that the study of Moreira et al. (18) might contribute to the heterogeneity in the analysis for ACM. Interestingly, that study had the largest number of patients and the smallest $95 \% \mathrm{CI}$ (18). It is possible that heterogeneity might become lower if other studies had had more patient samples. Subgroup analyses showed that variations in study quality and pathological type might also contribute to heterogeneity.

\section{Conclusion}

In conclusion, this meta-analysis indicates that preoperative anemia appears to be associated with earlier recurrence and shorter survival of patients undergoing radical or partial nephrectomy for RCC. Our findings, however, still need to be validated by well-designed prospective studies with large sample size and good control of confounding factors.

\section{Conflicts of Interest}

No conflicts of interest.

\section{References}

1 Ljungberg B, Bensalah K, Canfield S, Dabestani S, Hofmann F, Hora M, Kuczyk MA, Lam T, Marconi L, Merseburger AS, Mulders P, Powles T, Staehler M, Volpe A and Bex A: EAU Guidelines on Renal Cell Carcinoma: 2014 update. Eur Urol 67(5): 913-924, 2015.

2 Leibovich BC, Blute ML, Cheville JC, Lohse CM, Frank I, Kwon ED, Weaver AL, Parker AS and Zincke H: Prediction of progression after radical nephrectomy for patients with clear cell renal cell carcinoma: A stratification tool for prospective clinical trials. Cancer 97(7): 1663-1671, 2003.

3 Sun M, Shariat SF, Cheng C, Ficarra V, Murai M, Oudard S, Pantuck AJ, Zigeuner R and Karakiewicz PI: Prognostic factors and predictive models in renal cell carcinoma: A contemporary review. Eur Urol 60(4): 644-661, 2011.

$4 \mathrm{Hu} \mathrm{K}$, Lou L, Ye J and Zhang S: Prognostic role of the neutrophil-lymphocyte ratio in renal cell carcinoma: A metaanalysis. BMJ Open 5(4): e006404, 2015.

5 Grimes N, Tyson M, Hannan C and Mulholland C: A systematic review of the prognostic role of hematologic scoring systems in patients with renal cell carcinoma undergoing nephrectomy with curative intent. Clin Genitourin Cancer 14(4): 271-276, 2016.

6 Knight K, Wade S and Balducci L: Prevalence and outcomes of anemia in cancer: A systematic review of the literature. Am J Med 116(Suppl 7A): 11S-26S, 2004.

7 Brookman-Amissah S, Kendel F, Spivak I, Pflanz S, Roigas J, Klotz T and May M: Impact of clinical variables on predicting disease-free survival of patients with surgically resected renal cell carcinoma. BJU Int 103(10): 1375-1380, 2009.

8 Chen Z, Shao Y, Fan M, Zhuang Q, Wang K, Cao W, Xu X and $\mathrm{He} X$ : Prognostic significance of preoperative $\mathrm{C}$-reactive protein: Albumin ratio in patients with clear cell renal cell carcinoma. Int J Clin Exp Pathol 8(11): 14893-14900, 2015.

9 Cho DS, Kim SJ, Lee SH, Ahn HS, Kim YS and Kim SI: Prognostic significance of preoperative c-reactive protein elevation and thrombocytosis in patients with non-metastatic renal cell carcinoma. Korean J Urol 52(2): 104-109, 2011. 
10 Grivas N, Kafarakis V, Tsimaris I, Raptis P, Hastazeris K and Stavropoulos NE: Clinico-pathological prognostic factors of renal cell carcinoma: A 15-year review from a single center in greece. Urol Ann 6(2): 116-121, 2014.

11 Huang J, Feldman AS, Dong L, Cornejo K, Liu Q, Dahl DM, Wu S, Blute ML, Huang Y and Wu CL: Preoperative anemia as an independent prognostic indicator of papillary renal cell carcinoma. Clin Genitourin Cancer 13(5): e353-360, 2015.

12 Hutterer GC, Krieger D, Mrsic E, Pohlmann K, Bezan A, Stojakovic T, Pummer K, Zigeuner $\mathrm{R}$ and Pichler $\mathrm{M}$ : Preoperative leucocytosis, thrombocytosis and anemia as potential prognostic factors in non-metastatic renal cell carcinoma. Anticancer Res 35(6): 3463-3469, 2015.

13 Jensen HK, Donskov F, Marcussen N, Nordsmark M, Lundbeck $\mathrm{F}$ and von der Maase $\mathrm{H}$ : Presence of intratumoral neutrophils is an independent prognostic factor in localized renal cell carcinoma. J Clin Oncol 27(28): 4709-4717, 2009.

14 Jeon HG, Choi DK, Sung HH, Jeong BC, Seo SI, Jeon SS, Choi HY and Lee HM: Preoperative prognostic nutritional index is a significant predictor of survival in renal cell carcinoma patients undergoing nephrectomy. Ann Surg Oncol 23(1): 321-327, 2016.

15 Kaffenberger SD, Lin-Tsai O, Stratton KL, Morgan TM, Barocas DA, Chang SS, Cookson MS, Herrell SD, Smith JA Jr. and Clark PE: Statin use is associated with improved survival in patients undergoing surgery for renal cell carcinoma. Urol Oncol 33(1): 21e11-27, 2015.

16 Koie T, Ohyama C, Mikami J, Iwamura H, Fujita N, Sato T, Kojima Y, Fukushi K, Yamamoto H, Imai A, Hatakeyama S, Yoneyama T, Hashimoto $\mathrm{Y}$, Kitayama $\mathrm{M}$ and Hirota $\mathrm{K}$ : Preoperative butyrylcholinesterase level as an independent predictor of overall survival in clear cell renal cell carcinoma patients treated with nephrectomy. ScientificWorldJournal 2014: 948305, 2014

17 Komai Y, Saito K, Sakai K and Morimoto S: Increased preoperative serum c-reactive protein level predicts a poor prognosis in patients with localized renal cell carcinoma. BJU Int 99(1): 77-80, 2007

18 Moreira DM, Gershman B, Lohse CM, Boorjian SA, Cheville JC, Leibovich BC and Thompson RH: Paraneoplastic syndromes are associated with adverse prognosis among patients with renal cell carcinoma undergoing nephrectomy. World J Urol 34(10): 1465-1472, 2016

19 Sasaki T and Onishi T: Pretherapeutic plasma fibrinogen level is an independent survival predictor in renal cell carcinoma. Oncol Res Treat 38(7-8): 374-378, 2015.

20 Yap NY, Ng KL, Ong TA, Pailoor J, Gobe GC, Ooi CC, Razack $\mathrm{AH}$, Dublin N, Morais C and Rajandram R: Clinical prognostic factors and survival outcome in renal cell carcinoma patients a Malaysian single-centre perspective. Asian Pac J Cancer Prev 14(12): 7497-7500, 2013.

21 Moher D, Liberati A, Tetzlaff J, Altman DG and Group P: Preferred reporting items for systematic reviews and metaanalyses: The prisma statement. PLoS Med 6(7): e1000097, 2009.
22 Hayden JA, van der Windt DA, Cartwright JL, Cote P and Bombardier C: Assessing bias in studies of prognostic factors. Ann Intern Med 158(4): 280-286, 2013.

23 Caro JJ, Salas M, Ward A and Goss G: Anemia as an independent prognostic factor for survival in patients with cancer: A systemic, quantitative review. Cancer 91(12): 22142221, 2001

24 Rink M, Sharifi N, Fritsche HM, Aziz A, Miller F, Kluth LA, Ngamsri T, Dahlem R, Chun FK, Shariat SF, Stenzl A, Fisch M and Gakis G: Impact of preoperative anemia on oncologic outcomes of upper tract urothelial carcinoma treated with radical nephroureterectomy. J Urol 191(2): 316-322, 2014.

25 Gierth M, Mayr R, Aziz A, Krieger S, Wullich B, Pycha A, Lodde M, Salvadori U, Brundl J, Fritsche HM, Hofstadter F, Pawlik MT, Otto W, May M, Burger M and Denzinger S: Preoperative anemia is associated with adverse outcome in patients with urothelial carcinoma of the bladder following radical cystectomy. J Cancer Res Clin Oncol 141(10): 1819$1826,2015$.

26 Clarke $\mathrm{H}$ and Pallister CJ: The impact of anaemia on outcome in cancer. Clin Lab Haematol 27(1): 1-13, 2005.

27 Linder BJ, Thompson RH, Leibovich BC, Cheville JC, Lohse CM, Gastineau DA and Boorjian SA: The impact of perioperative blood transfusion on survival after nephrectomy for non-metastatic renal cell carcinoma (RCC). BJU Int 114(3): 368-374, 2014.

28 Fan Y, Li H, Ma X, Gao Y, Chen L, Li X, Bao X, Du Q, Zhang Y and Zhang X: Prognostic significance of hypoxia-inducible factor expression in renal cell carcinoma: A prisma-compliant systematic review and meta-analysis. Medicine 94(38): e1646, 2015.

29 Karakiewicz PI, Suardi N, Capitanio U, Jeldres C, Ficarra V, Cindolo L, de la Taille A, Tostain J, Mulders PF, Bensalah K, Artibani W, Salomon L, Zigeuner R, Valeri A, Descotes JL, Rambeaud JJ, Mejean A, Montorsi F, Bertini R and Patard JJ: A preoperative prognostic model for patients treated with nephrectomy for renal cell carcinoma. Eur Urol 55(2): 287-295, 2009.

30 Patard J-J, Kim HL, Lam JS, Dorey FJ, Pantuck AJ, Zisman A, Ficarra V, Han K-R, Cindolo L, De La Taille A, Tostain J, Artibani W, Dinney CP, Wood CG, Swanson DA, Abbou CC, Lobel B, Mulders PFA, Chopin DK, Figlin RA and Belldegrun AS: Use of the University of California Los Angeles integrated staging system to predict survival in renal cell carcinoma: An international multicenter study. J Clin Oncol 22(16): 3316-3322, 2004.

Received March 27, 2017

Revised April 15, 2017

Accepted April 19, 2017 